\title{
ENDOGENOUS INTOXICATION IN ANIMALS OF DIFFERENT AGE GROUPS IN CASE OF POLYTRAUMA
}

\author{
S. R. Pidruchna, H. M. Stepanova, B. O. Pereviznyk, N. A. Vasylyshyn, \\ A. A. Hudyma, L. S. Donchenko \\ I. HORBACHEVSKY TERNOPIL STATE MEDICAL UNIVERSITY, TERNOPIL, UKRAINE
}

\begin{abstract}
Background. Associated injury is a worldwide social and economic problem. Age related aspects of endogenous intoxication are not studied comprehensively. Annually, from 44000 to 65000 citizens die because of traumatic injuries. As a result, this number increased by $32.6 \%$ for the last 10 years. The detoxification system, as a component of the functional systems of the organism, experiences significant changes in case of polytrauma.

Objective. The study was aimed to discover pathogenetic peculiarities of the multiple trauma in age aspect in different disease periods and to explore the level of endogenous intoxication in this condition.

Methods. The experiments were performed on 72 white male rats aged 3, 6 and 12 months, which underwent simulation of severe skeletal trauma and examination of the contents of middle mass molecules and endogenous intoxication index (markers of endogenous intoxication) in 1, 4 and 24 hours after the associated injury.

Results. The most significant increase of the middle mass molecules was fixed in 24 hours after modeling of severe skeletal injuries in all groups of animals, especially it was the most pronounced in 12-month-old animals. The erythrocyte intoxication index reached the highest level in 4 hours after the injury, its increase was most significant in sexually mature adult animals.

Conclusions. A significant increasing of endogenous intoxication markers in 12-month-old rats, if compared to 3- and 6-month-old animals, can be caused by the decrease in compensatory protection mechanisms.
\end{abstract}

KEY WORDS: multiple trauma, endogenous intoxication, age.

\section{Introduction}

These days, the increased number of associated is one of the most important social and economic problems [1-7].

In Ukraine the mortality rate, as a consequence of injury, is $91.8 \%$ of cases per 100000 citizens. Annually, from 44000 to 65000 citizens die because of traumatic injuries. As a result, this number increased by $32.6 \%$ for the last 10 years.

The detoxification system, as a component of the functional systems of the organism, experiences significant changes in case of multiple trauma. The disturbance of functioning of this system leads to the development of endogenous intoxication syndrome (EIS), which causes the primary diseases and the complications due to increased tissue decay, escalation of catabolic processes, insufficient

Corresponding author: Svitlana Pidruchna, Department of Medical Biochemistry, I. Horbachevsky Ternopil State Medical University, 1 Maidan Voli, Ternopil, Ukraine, 46001

Phone number: +380352254784

E-mail: pidruchna@tdmu.edu.ua functioning of internal organs [11, 12]. Among the causes of death during terminal stage are multiple organ failure and consistent progressive failure of organ systems as a result of injury.

Nowadays the age-related mechanisms of EIS development are not studied comprehensively. There are no complete pathogenetic approaches to the explanation and prognosis of early and late complications of multiple trauma.

The study was aimed to discover pathogenetic peculiarities of the multiple trauma in age aspect in different disease periods and to explore the level of endogenous intoxication in this condition.

\section{Material and Methods}

In this experimental study we used 72 white rats of the age of 3,6 , and 12 months old. The experimental model of multiple trauma was implemented during the study [9]. The control group was comprised of intact animals, which 
were kept under the standard vivarium conditions. Decapitation was accomplished under thiopental anaesthesia on $1^{\text {st }}, 4^{\text {th }}$, and $24^{\text {th }}$ hour of the experiment in accordance to The European Convention for the Protection of Vertebrate Animals Used for Experimental and other Scientific Purposes (Strasbourg, 1986). We used blood serum for the research. The degree of toxic syndrome was evaluated by the level of middle mass molecules (MMM) [8] and erythrocyte intoxication index (EII) [10]. The received data was processed by method of statistical variation and Student t-test. The results were considered as significant at the value $p<0.05$.

\section{Results and Discussion}

In our experiment we detected the significant changes of MMM in all 3 animal groups and compared the results with the intact ones.

In the 3-month-old rats the increase of $\mathrm{MMM}_{254}$ was observed during the $1^{\text {st }}$ hour after multiple trauma. The level of these molecules increased by $39 \%$, and after 4 hours it was $48 \%$ if compared to the intact animals. On the $1^{\text {st }}$ day after the multiple trauma $\mathrm{MMM}_{254}$ was on $43 \%$ higher than normal rates.
The similar changes were observed in the 6-month-old rats. During the $1^{\text {st }}$ hour the $\mathrm{MMM}_{254}$ was increasing even by $73 \%$, in 4 hours - by $83 \%$ and in 1 day of the experiment it was by $79 \%$ higher than in the intact group.

The most significant increase in $\mathrm{MMM}_{254}$ was evidenced in the 12-month-old animals. After the $1^{\text {st }}$ hour it increased by $93 \%$, in 4 hours - by $96 \%$ if compared to the intact animals, in 1 day - more than in 2 times.

The increase of MMM level in animals after multiple trauma proved the enforcement of catabolic processes. The rise of MMM levels, which can include oligopeptides, fragments of nucleic acids, fatty acids, and triglycerides, can prove the injury of the hepatocytes membranes and $\mathrm{MMM}_{254}$ that include purine bases, uric acid and aromatic amino acids - the suppression of the detoxifying function of liver [13].

The differences in the dynamics of changes of $\mathrm{MMM}_{280}$ between the $1^{\text {st }}, 2^{\text {nd }}$ and $3^{\text {rd }}$ groups were manifested (Fig. 2).

After the multiple trauma the level of $\mathrm{MMM}_{280}$ in the 3-month-old animal group was higher by $82 \%$ if compared to intact animals. In 4 hours it was exceeding the level of control group by $108 \%$, in 1 day - by $98 \%$.

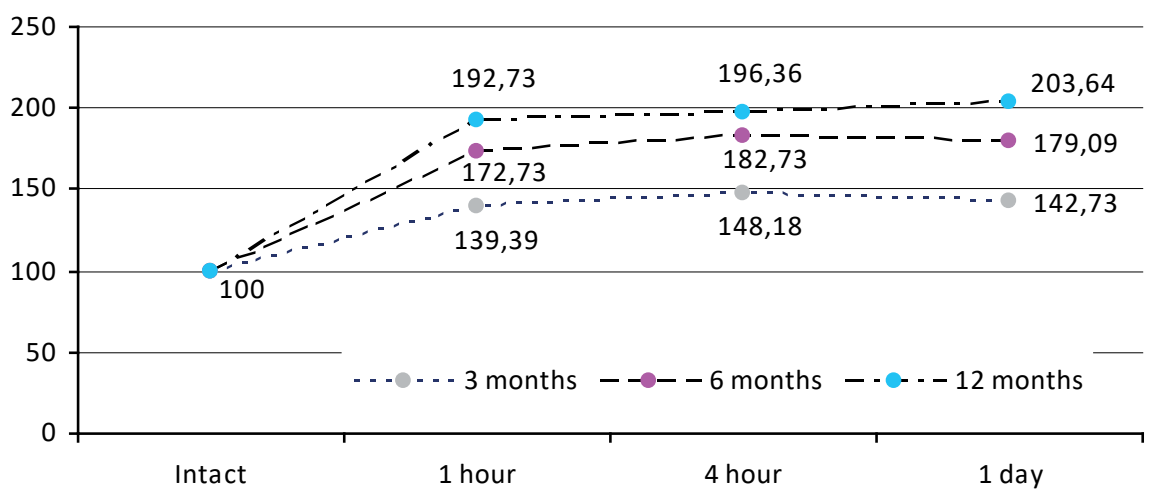

Fig. 1. The level of $\mathrm{MMM}_{254}$ in rats of different age after multiple trauma (in percentage if compared to the level of the intact animals) in dynamics.

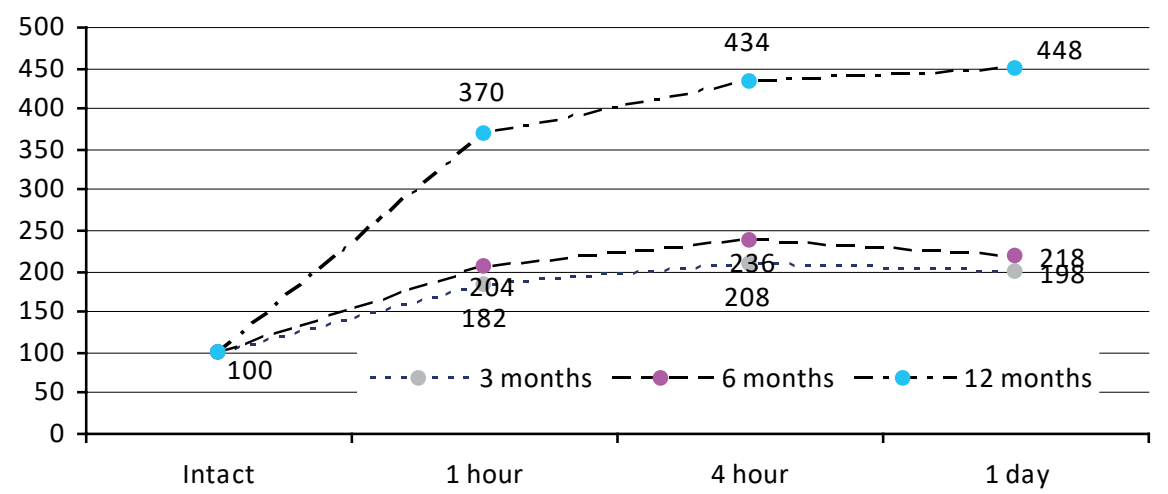

Fig. 2. The level of $\mathrm{MMM}_{280}$ in rats of different age after multiple trauma (in percentage if compared to the level in the intact animals) in dynamics. 
In the 6-month-old group $\mathrm{MMM}_{280}$ was higher by $104 \%$ if compared to the control group, in 4 and 24 hours - by $136 \%$ and $98 \%$ respectively.

The highest level of $\mathrm{MMM}_{280}$ was observed in the 12-month-old animals in all periods of the experiment. In 1 hour after multiple trauma, it was exceeding the level of the intact animals by $270 \%$, in 4 hours - by $344 \%$, in 1 day - by $448 \%$.

We argue that the increase in MMM levels is a manifestation of catabolic processes enforcement in cells of vital tissues. The possible cause for these changes can be the activation of intracellular, particularly lysosomal proteases under the influence of these toxins [14].

The multiple trauma also influenced on the level of erythrocyte membranes impairment (Fig. 3).
EII significantly increased during the $1^{\text {st }}$ hour after multiple trauma in the 3-month-old rats and exceeded the level of the intact animals by $85 \%$. In 4 and 24 hours of the experiment it increased by $97 \%$ and $92 \%$ respectively.

In the 6-month-old rats, in 1 hour the EII was higher than in the intact animals by $107 \%$, in 4 hours - by $124 \%$, in 1 day - by $213 \%$.

In the 12-month-old rats, in 1 hour the EII was higher by $127 \%$ if compared to the intact rats, in 4 hours - by $245 \%$, and in 1 day - by $149 \%$. In case of MMM the EII reached the highest level.

The data obtained prove the action potentiation of endogenous toxins that are excreted to blood in case of multiple trauma; it can be accompanied by either high level of catabolic processes or the suppression of the detoxification system functional activity [15].

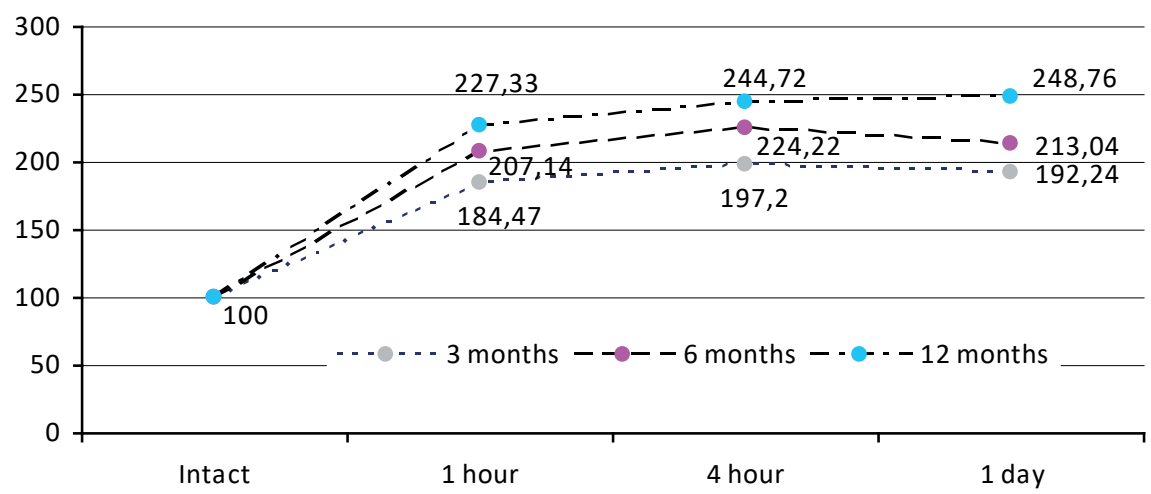

Fig. 3. The level of EII in rats of different age after multiple trauma (in percentage if compared to the level of the intact animals) in dynamics.

\section{Conclusions}

MMM and EII proved serious age-related differences between the animals with multiple trauma. In all animal groups the highest value was reached during the $1^{\text {st }}$ hour after the injury and continued with concomitant slow decline, especially in the 3- and 6-month-old animals in 4 hours after the injury. However, in the

\section{References}

1. Asehnoune $K$, Edouard A. Inflammatory response and polytrauma: an update. Reanimation 2006; 15: 568-575.

2. Balogh Z, Varga E, Tomka J, et al. The New Injury Severity Score Is a Better Predictor of Extended Hospitalization and Intensive Care Unit Ad- 12-month-old rats the increase of MMM and EII continued; it proved prolongation of endogenous intoxication.

The further research on endogenous intoxication will broaden the view on the pathogenesis of traumatic diseases in people of different age and in various periods of the diseases that will provide the opportunity to make prognoses on further course of the disease. 
4. Dimar JR, Carreon LY, Riina J, et al. Early versus late stabilization of the spine in the polytrauma patient. Spine 2010; 35: 187-192.

5. Hildebrand F, Giannoudis P, Kretteck C, Pape H. Damage control: extremities. Injury 2004; 35: 678-689.

6. Huber-Lang M, Wiegner R, Lamp L, Rolf E. Brenner Mesenchymal Stem Cells after Polytrauma: Actor and Target Stem. Cells International 2016; 10.

7. Pomeranz, JL, Shaw LR, Yu NS, Moorhouse MD. Polytrauma and life care planning: Managing the complex interaction of multiple injuries. Work 2008; 31(3): 319-326.

8. Andreichyn MA, Bekh MD, Demyanenko VV. Method of diagnosis of endogenous intoxication of organism: methodical recommendations 1998: 1013. (In Ukrainian).

9. Sekela TIa, Hudyma AA. Patent for the Utility Model 30028 Ukraine IPC 2006 G 09B 23/00. Modeling method of polytrauma. Ternopil Medical University. U 2007 10471; Stated. 21.09.2007; Published.11.02.08; Biul. 3: 4. (In Ukrainian).

10. Togaybaiev AA, Kurguzkin AV, Rikun IV, Karib- zhanova RM. Method of diagnosis of endogenous intoxication. Lab. Work 1988; 9: 22-24. (In Russian).

11. Valdmol BM, Volchehorskyi YV, Puzhevskyi AS, et al. Middle molecular peptides of blood as endogenous regulators of lipids peroxidation in normal and thermal burns. Medical chemistry questions 1991; 37 (1): 23-26. (In Russian).

12. Erokhyn YA, Havrylyn SV, Nemchenko NS. Endotoxicosis with severe concomitant injury. Surgery journal2001; 160 (5): 120-124. (In Russian).

13. Kyshkun AA, Kudynova AS, Ofytova AD, Myshuryna RB. Value of average molecules in appreciation of the endogenous intoxication level Militarymedical journal 1990; 2: 41-44. (In Russian).

14. Pidruchna SR, Vasylyshyn N A, Kulyanda OO, Kulyanda IS. Corrective effect of xenodermoplasticson the indexes of endogenous intoxication in severe injury. Medical chemistry 2011; 13 (1) 58-62. (In Ukrainian).

15. Kulyanda OO, Pidruchna SR, Kulyanda IS, Zakharchuk UM, Ostrivka OI. The dynamics of endogenous intoxication in severe injury. Pain. Anesthesia and intensive care 2010; 2: 54-58. (In Ukrainian). 